\title{
Proteinuria after Kidney Transplantation
}

\author{
Marius Miglinas ${ }^{1^{*}}$, Arvydas Laurinavicius ${ }^{2}$ and Diana Lukasevic ${ }^{1}$ \\ ${ }^{1}$ Vilnius University, Nephrology Center, Lithuania
}

${ }^{2}$ Vilnius University, National Center of Pathology, Lithuania

\begin{abstract}
Proteinuria is a significant complication affecting renal transplant recipients. It is linked to cardiovascular events, a premature death and graft loss. The prevalence of proteinuria is close to $40 \%$ of renal transplant recipients per year. The causes of proteinuria are multiple: glomerular disease, anti-HLA class II antibodies, various medications and tubulointerstitial disease of the graft. It is very important to evaluate the cause of proteinuria, to reduce proteinuria and cardiovascular risk.
\end{abstract}

Keywords: Proteinuria; Kidney transplantation; Transplant glomerulopathy

\section{Introduction}

Proteinuria is very common non-specific sign of the renal allograft injury. In kidney transplant recipients, the prevalence of proteinuria varies substantially and ranges between $11 \%$ and $45 \%$. It depends on criteria for proteinuria definition and partly on the time passed after the transplant procedure [1]. Majority of the authors investigated proteinuria 1 year after kidney transplantation. In studies with a diagnosis of proteinuria as a high content of protein (exceeding $2-3 \mathrm{~g} / \mathrm{d}$ ), the prevalence varied from $12.1 \%$ to $13.7 \%[2,3]$. When the cutoff value exceeded $1 \mathrm{~g} / \mathrm{d}$, the prevalence of post-transplant proteinuria ranged from $7.5 \%$ to $40 \%[4,5]$. The highest prevalence of post-transplant proteinuria up to almost $50 \%$ was when the classic threshold for proteinuria $(>150 \mathrm{mg} / \mathrm{d})$ was used [6]. Proteinuric patients have worse graft survival and mortality rates in comparison with non-proteinuric patients. Proteinuria also increases risk of cardiovascular events $[4,7,8]$. Plenty of data suggest that proteinuria is associated with up to four times increased risk for graft failure [9]. Roodnat et al. showed in their study that the risk for death increased by $16 \%$ (95\% Confidence Interval [CI] 8 to $26 \%$ ) for each $1.0 \mathrm{~g} / \mathrm{d}$ increase in proteinuria [8].

Proteinuria is frequently seen immediately after transplantation. The reason can be the native kidney or the allograft, probably as a consequence of the ischemia-reperfusion injury. Proteinuria falls after successful kidney transplantation within few weeks. The residual or late proteinuria represents graft injury.

There are two main mechanisms which can cause proteinuria after kidney transplantation: an inadequate reabsorption of small proteins from proximal tubular cells and an increased passage of albumin or protein with higher molecular weight. The types and amounts of proteins appearing in the urine may indicate the specific transplant injury or pathologic condition. In post-transplant glomerular disease the proteinuria usually is nonselective with a high urinary immunoglobin $\mathrm{G}$ (IgG)/albumin rate [10]. IgG is a highmolecular-weight protein $(150 \mathrm{kd})$ that is not filtered in glomerulus under physiologic conditions because of pore width. By appearing in urine it reflects the intense glomerular injury and impairment of membrane selectivity [11]. Proteinuria exceeding $1.5 \mathrm{~g} / \mathrm{d}$ is a feature suggestive of glomerular disease as well [12]. High levels of proteinuria are associated with transplant glomerulopathy, recurrent or de novo glomerulonephritis, focal glomerulosclerosis caused by chronic calcineurin inhibitors toxicity [13]. Low-grade proteinuria up to 0.5 $\mathrm{g} / \mathrm{d}$ would reflect tubular compartment injury. The diminished tubular reabsorption affects various low-molecular-weight proteins $(21-\mathrm{kd}$ retinol-binding protein, $12-\mathrm{kd} \beta-2$ microglobulin). The reasons of tubular proteinuria are acute rejection, ischemia-reperfusion injury, nephrotoxic agents (certain antibiotics, antiviral drugs). The Spare-theNephron trial showed that sirolimus significantly increases proteinuria in comparison with calcineurin inhibitors [14]. The two types of proteinuria are interrelated. Glomerular damage may impact tubular interstitium and tubulointerstitial changes may create glomerular lesions. In advanced forms of transplant disease mixed (tubular and glomerular) patterns of proteinuria are frequently found [15].

\section{How to Monitor Proteinuria?}

The 2009 Kidney Disease: Improving Global Outcomes (KDIGO) clinical practice guideline on the care of the kidney transplant recipient recommended to measure urine protein excretion at least once within the first month after transplantation, every 3 months during the first year and annually later on. For the new-onset proteinuria or unexplained nephrotic proteinuria renal allograft biopsy should be performed. Proteinuria and albuminuria can be quantified with a 24hour collection or by using spot urine collections (Albumin-Creatinine Ratio (ACR) or Protein-Creatine Ratio (PCR)). KDIGO suggest that $\mathrm{ACR}$ and PCR are reasonable screening tests in the renal transplant recipients. The positive tresholds for proteinuria have been established to be $>250$ (men) or $>355$ (women) $\mathrm{mg} / \mathrm{g}$ by ACR and $>200 \mathrm{mg} / \mathrm{g}$ by PCR [16]. The KDIGO guidelines recommend monitoring of proteinuria as part of routine transplant follow-up. Any positive screen should be confirmed by a 24-hour urine collection. For the daily practice the above recommendations mean that regular-monitoring of the amount of proteinuria at all follow-up visits is very important. Twenty-four hour urine protein excretion is the gold standard for quantitative protein assessment. If the $24 \mathrm{~h}$ urine collection is problematic, the urinary protein/creatinine ( $\mathrm{mg} / \mathrm{g}$ ) ratio assessed in'spot' urine is an excellent surrogate, as it has proved to have an excellent correlation with the protein content of a $24-\mathrm{h}$ urine collection [17]. The KDIGO also suggest biopsy for unexplained proteinuria $>3 \mathrm{~g} / \mathrm{d}$.

\section{Kidney Transplant Biopsy Pathology in Proteinuria}

Several studies have reported allograft pathology findings in

${ }^{*}$ Corresponding author: Marius Miglinas, Nephrology Center, Vilnius University Hospital Santariskiu Klinikos Santariskiu 2, LT-08661 Vilnius, Lithuania, Fax: +370 52365111; E-mail: Marius.Miglinas@santa.It

Received October 29, 2013; Accepted December 18, 2013; Published December 23, 2013

Citation: Miglinas M, Laurinavicius A, Lukasevic D (2013) Proteinuria after Kidney Transplantation. J Nephrol Ther 4: 145. doi:10.4172/2161-0959.1000145

Copyright: (c) 2013 Miglinas M, et al. This is an open-access article distributed under the terms of the Creative Commons Attribution License, which permits unrestricted use, distribution, and reproduction in any medium, provided the original author and source are credited. 
patients with proteinuria. Lopez et al. in their study reported that the most common pathology was glomerular disease (51\%) including transplant glomerulonephropathy, glomerulonephritis and diabetic nephropathy [7]. Most of patients had more than one histological lesion, including interstitial fibrosis and tubular atrophy, which was present in $85 \%$ of the biopsies. The therapeutic measures after biopsy stabilized renal function and reduced proteinuria. Transplant glomerulopathy is characterized by specific morphological changes such as layering of capillary basement membranes, identified by light microscopy as a duplication of the glomerular basement membrane (Figure 1). Typically it leads to proteinuria and is usually associated with a poor prognosis for kidney graft survival. Transplant glomerulopathy is widely accepted as the principal manifestation of chronic antibody-mediated rejection, mostly with HLA antigen class II antibodies. Lopez et al. showed in the other study that transplant glomerulopathy is frequently associated with worsening renal function and the development of high-grade proteinuria [18].

\section{How to Manage Proteinuria?}

In many causes, in particular for transplant glomerulopathy and chronic antibody-mediated rejection, no effective treatment is available. Usually treatment of proteinuria is symptomatic. The antiproteinuric measures available for several native kidney diseases may be applied to transplant kidney patients with proteinuria [9]. These measures should include Blood Pressure (BP) control (to systolic pressure $<130 \mathrm{mmHg}$ ). The most important aim of proteinuria's treatment is to avoid glomerular hypertension. The renin-angiotesin system's inhibitors (RAS) are very

\section{A}

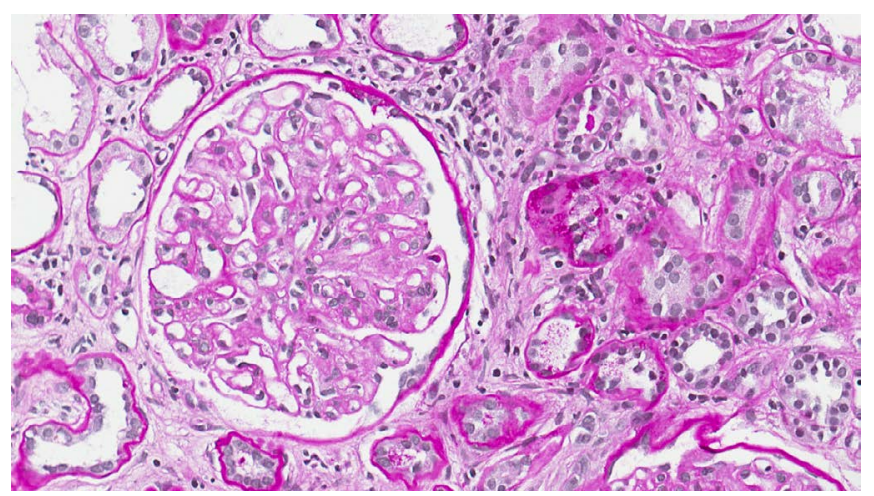

B

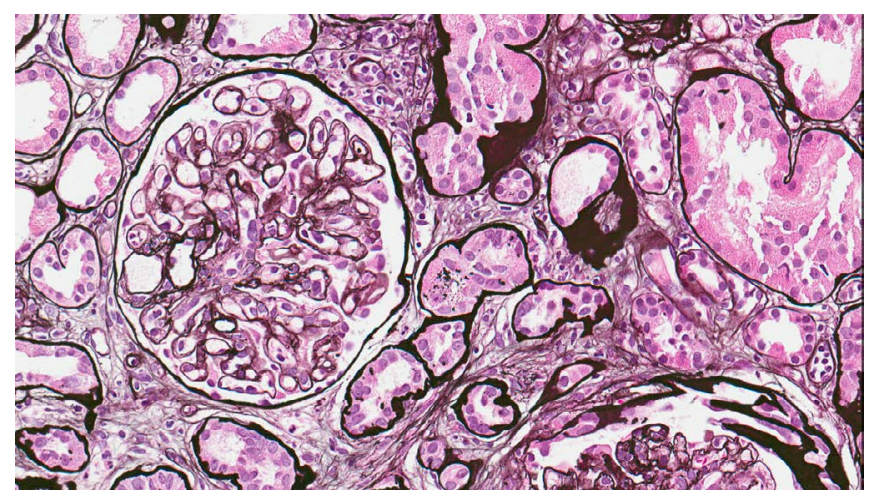

Figure 1: Chronic transplant glomerulopathy with double contours and thickening of glomerular capillary walls, (A) PAS and (B) methamine-silver stain. effective in minimizing microalbuminuria and proteinuria in kidney transplant recipients. The benefit of Angiotensin-Converting Enzyme Inhibitors (ACEIs) or an Angiotensin II Receptor Blockers (ARBs) for the reduction of proteinuria in the kidney transplant population has been shown in several clinical trials. In 2003 Omoto et al. reported a significant reduction in post-transplant proteinuria exceeding $50 \%$ of baseline levels by ARB candesartan in doses of 4 to $12 \mathrm{mg} / \mathrm{d}$ [19]. Recent large scale SECRET study $(n=502)$ published by Philipp et al. again showed a significant decrease of proteinuria in the candesartan group compared to the placebo group [20].

A meta-analysis of 21 randomized controlled trials comparing an ACEIs or ARBs with a control arm using placebo or another active medication has been published in 2007 [21]. The study included 1549 kidney transplant recipients. The median follow-up time was 27 months. Among the 21 studies analyzed, 4 trials included results on proteinuria. In all of these 4 studies a significant decline of this parameter has been reported [21]. However, the question remains whether proteinuria reduction by ACEIs or ARBs translates into a measurable benefit in terms of an increase in graft and patient survival. This has not yet been demonstrated in properly designed clinical trials. Thus, the blockade of the RAS with ACEIs or ARBs may reduce proteinuria, but the long-term effect of these agents on patient and graft survival remains to be evaluated in future studies [22-25]. In addition, RAS modulation besides that provided by ACEIs and ARBs may be beneficial. Further blockade could be provided by direct renin inhibition (aliskiren). ACE2 activation might be another therapeutic strategy [24]. Patients taking ACEIs or ARBs must be monitored for the toxicity of immunosuppressive drugs, anemia, hyperkalemia, allograft dysfunction, cough and angioedema [23].

In addition, treatment of vitamin $\mathrm{D}$ analogs seems to have a beneficial antiproteinuric effect through down regulating renin synthesis. Various therapies that reduce or inhibit the progression of renal fibrosis are being investigated as strategies to decrease proteinuria. Promising results have been obtained with pentoxifylline, and antifibrotic agents, but further studies are awaited to confirm these preliminary results [24].

Other measures to reduce proteinuria in kidney transplant recipients should include lipid control, preferably with a statin, nicotin cessation and body weight reduction [26-28]. Also, proteinuric patients should be adviced to consume a diet with a moderate protein and low sodium content. For high-risk groups, such as patients with chronic kidney disease, a sodium intake of not exceeding $1.5 \mathrm{~g} \mathrm{(} \sim 70 \mathrm{mmol} /$ day) is advocated [29]. Mean daily sodium intake in kidney transplant recipients exceeds current international guidelines. This finding has been shown in several previous reports with a mean 24-h urinary sodium excretion rates of 178 and $224 \mathrm{mmol} / 24 \mathrm{~h}$, respectively [30,31]. The recent data show that even a modest reduction in dietary sodium intake may be very beneficial in kidney patients [32]. High dietary sodium is related to increased albuminuria [33]. It also may decrease the anti-proteinuric benefits of RAS blockade [34]. There are just a few studies published in 1990s, which investigated the effect of dietary protein restriction in reducing post-transplant proteinuria. It has been shown a significant reduction in proteinuria with protein restriction of 0.55 or $0.70 \mathrm{~g} / \mathrm{kg} / \mathrm{d}$ [16]. However, there are no data about impact of dietary protein restriction on long-term kidney function or allograft survival and overall nutritional status of renal transplant recipients. The safety of protein restriction as a therapeutic mean still waits to be assessed in future studies before it could be recommended. 
Citation: Miglinas M, Laurinavicius A, Lukasevic D (2013) Proteinuria after Kidney Transplantation. J Nephrol Ther 4: 145. doi:10.4172/21610959.1000145

Page 3 of 3

\section{Conclusions}

Residual proteinuria is a significant complication and an independent risk factor for graft and recipient survival. Proteinuria after kidney transplantation can occur as a consequence of allograft injury (acute rejection, delayed graft function, chronic allograft nephropathy), use of mTOR inhibitors or as recurrent kidney disease (amyloidosis, focal segmental glomerulosclerosis, membranoproliferative glomerulonephritis, diabetic nephropathy). Kidney biopsy helps to recognize the etiology of proteinuria. The most common pathology is glomerular disease. However, in contrast to native kidney disease patients, proteinuric kidney transplant recipients have more transplant-related lesions such as allograft nephropathy, transplant glomerulopathy or acute rejection. ACEIs and ARBs significantly reduce proteinuria in the kidney transplant population. Lipid control, dietary sodium reduction, nicotin cessation and weight loss all are an important part of post-transplant proteinuria management.

\section{References}

1. Knoll GA (2009) Proteinuria in kidney transplant recipients: prevalence, prognosis, and evidence-based management. Am J Kidney Dis 54: 1131-1144.

2. Fernández-Fresnedo G, Escallada R, Rodrigo E, De Francisco AL, Cotorruelo JG, et al. (2002) The risk of cardiovascular disease associated with proteinuria in renal transplant patients. Transplantation 73: 1345-1348.

3. Yakupoglu U, Baranowska-Daca E, Rosen D, Barrios R, Suki WN, et al. (2004) Post-transplant nephrotic syndrome: A comprehensive clinicopathologic study. Kidney Int 65: 2360-2370.

4. Fernández-Fresnedo G, Plaza JJ, Sánchez-Plumed J, Sanz-Guajardo A Palomar-Fontanet R, et al. (2004) Proteinuria: a new marker of long-term graft and patient survival in kidney transplantation. Nephrol Dial Transplant 19 Supp 3: $47-51$

5. Park JH, Park JH, Bok HJ, Kim BS, Yang CW, et al. (2000) Persistent proteinuria as a prognostic factor for determining long-term graft survival in renal transplant recipients. Transplant Proc 32: 1924.

6. Melilli E, Cruzado JM, Bestard O, Hernández D (2012) Mechanisms and risk factors for the development of the proteinuria after kidney transplantation. Transplant Rev (Orlando) 26: 14-19.

7. López V, Sola E, Jironda C, León M, García I, et al. (2011) Biopsies in renal transplant patients with proteinuria: histological findings. Transplant Proc 43: 2191-2193.

8. Roodnat JI, Mulder PG, Rischen-Vos J, van Riemsdijk IC, van Gelder T, et al (2001) Proteinuria after renal transplantation affects not only graft survival but also patient survival. Transplantation 72: 438-444.

9. Amer H, Cosio FG (2009) Significance and management of proteinuria in kidney transplant recipients. J Am Soc Nephrol 20: 2490-2492.

10. Calabuig AS, Guirado L, Ramos D (2012) Prognostic significance and diagnosis of proteinuria in renal transplantation. Transplant Rev (Orlando) 26: 30-35.

11. Regeniter A, Freidank H, Dickenmann M, Boesken WH, Siede WH (2009) Evaluation of proteinuria and GFR to diagnose and classify kidney disease: systematic review and proof of concept. Eur J Intern Med 20: 556-561.

12. Amer H, Fidler ME, Myslak M, Morales P, Kremers WK, et al. (2007) Proteinuria after kidney transplantation, relationship to allograft histology and survival. Am J Transplant 7: 2748-2756.

13. Ponticelli C, Graziani G (2012) Proteinuria after kidney transplantation. Transp Int 25: 909-917.

14. Bumbea V, Kamar N, Ribes D, Esposito L, Modesto A, et al. (2005) Long-term results in renal transplant patients with allograft dysfunction after switching from calcineurin inhibitors to sirolimus. Nephrol Dial Transplant 20: 2517-2523.
15. Halimi JM, Matthias B, Al-Najjar A, Laouad I, Chatelet V, et al. (2007) Respective predictive role of urinary albumin excretion and nonalbumin proteinuria on graft loss and death in renal transplant recipients. Am J Transplant 7: 2775-2781.

16. Shamseddin MK, Knoll GA (2011) Posttransplantation proteinuria: an approach to diagnosis and management. Clin J Am Soc Nephrol 6: 1786-1793.

17. Ginsberg JM, Chang BS, Matarese RA, Garella S (1983) Use of single voided urine samples to estimate quantitative proteinuria. N Engl J Med 309: 15431546

18. López Jiménez V, Fuentes L, Jiménez T, León M, Garcia I, et al. (2012) Transplant glomerulopathy: clinical course and factors relating to graft survival. Transplant Proc 44: 2599-2600.

19. Omoto K, Tanabe K, Tokumoto T, Shimmura H, Ishida H, et al. (2003) Use of candesartan cilexetil decreases proteinuria in renal transplant patients with chronic allograft dysfunction. Transplantation 76: 1170-1174.

20. Philipp T, Martinez F, Geiger H, Moulin B, Mourad G, et al. (2010) Candesartan improves blood pressure control and reduces proteinuria in renal transplant recipients: results from SECRET. Nephrol Dial Transplant 25: 967-976.

21. Hiremath S, Fergusson D, Doucette S, Mulay AV, Knoll GA (2007) Renin angiotensin system blockade in kidney transplantation: a systematic review of the evidence. Am J Transplant 7: 2350-2360.

22. Ruiz JC, Sánchez-Fructuoso A, Zárraga S (2012) Management of proteinuria in clinical practice after kidney transplantation. Transplant Rev (Orlando) 26 $36-43$

23. Cruzado JM, Rico J, Grinyó JM (2008) The renin angiotensin system blockade in kidney transplantation: pros and cons. Transpl Int 21: 304-313.

24. Soler MJ, Riera M, Gutierrez A, Pascual J (2012) New options and perspectives for proteinuria management after kidney transplantation. Transplant Rev (Orlando) 26: 44-52.

25. Kaufeld J, Schiffer M, Chatzikyrkou C (2012) Pathogenesis and management of hypertension after kidney transplantation. Current Hypertension Reviews 8: 296-230.

26. Nakamura T, Sato E, Fujiwara N, Kawagoe Y, Takeuchi M, et al. (2010) Atorvastatin reduces proteinuria in non-diabetic chronic kidney disease patients partly via lowering serum levels of advanced glycation end products (AGEs) Oxid Med Cell Longev 3: 304-307.

27. Tylicki L, Puttinger H, Rutkowski P, Rutkowski B, Horl WH (2006) Smoking as a risk factor for renal injury in essential hypertension. Nephron Clin Pract 103 c121-128.

28. Praga M (2002) Obesity--a neglected culprit in renal disease. Nephrol Dial Transplant 17: 1157-1159.

29. U.S. Department of Agriculture and U.S. Department of Health and Human Services. Dietary Guidelines for Americans 2010 (16 December 2013, date last accessed)

30. Moeller T, Buhl M, Schorr U, Distler A, Sharma AM (2000) Salt intake and hypertension in renal transplant patients. Clin Nephrol 53: 159-163.

31. Kalbfleisch JH, Hebert LA, Lemann J Jr, Piering WF, Beres JA (1982) Habitua excessive dietary salt intake and blood pressure levels in renal transplant recipients. Am J Med 73: 205-210.

32. Lambers Heerspink HJ, Holtkamp FA, Parving HH, Navis GJ, Lewis JB, et al (2012) Moderation of dietary sodium potentiates the renal and cardiovascula protective effects of angiotensin receptor blockers. Kidney Int 82: 330-337.

33. Verhave JC, Hillege HL, Burgerhof JG, Janssen WM, Gansevoort RT, et al (2004) Sodium intake affects urinary albumin excretion especially in overweight subjects. J Intern Med 256: 324-330.

34. Lambers Heerspink HJ (2011). Therapeutic approaches in lowering albuminuria: travels along the renin-angiotensin-aldosterone-system pathway. Advances in Chronic Kidney Disease 18: 290-299. 